\title{
The Study of Communication Chinese in America from the History of the International Communication of Languages
}

\author{
Lin Zhu \\ College of Liberal Arts \\ Beijing International Studies University \\ Beijing, China 100024
}

\begin{abstract}
Language is a commodity in the process of international communication, and high added value is an important factor in the successful dissemination of contemporary languages. In the fiercely competitive language market, improving the added value of Chinese is an important means of spreading Chinese. As a super-super language, the successful communication experience of English shows us certain reference significance for the dissemination of Chinese. In the successful dissemination of language is to improve the national international influence. In the traditional Confucian cultural circle, China has a "prestige" status in terms of economy, thus ensuring the high value-added of Chinese. The paper discusses the positive correlation between trade, culture, science, technology, population reproduction, migration, education and the effects of language communication, and the paper demonstrates the importance of realizing the localization of Chinese teachers in the United States, which is one of the important factors.
\end{abstract}

Keywords-United States; Chinese international education; language communication history

\section{INTRODUCTION}

Language is an important gene of culture and ethnicity. It is one of the important distinguishing features that distinguish different cultures and ethnic groups. The unification of language use helps to use the cohesion of the linguistic group. Huntington puts forward that the importance of language is second only to religion, and language and religion are the main factors that constitute a country or a nation. From the perspective of the history of global language communication, different lingua Franca is constantly appearing in different periods. This article believes that these common words surpass the boundaries of the country and the nation in the scope of use. This language is called super language. For example, historically Latin, French, English, etc. These commonly-used linguistic languages that achieve better communication results are often because the countries behind the language have strong economic, military, and other strengths. These languages have high added value, thus guiding the dissemination of the audience to learn voluntarily.

From the perspective of the language pattern of the world today, the language that is well-distributed has the characteristics of high prestige and high added value. People in other countries are willing to acquire the common language, just for the reason of high added value of the language, not for subsidies given by the state of the target language. At the same time, the successful transmission of the super language has strong resources. Additional resources of the language will allow ethnic groups in other languagesto identify and transmit super-language and voluntarily take the initiative to acquire the language. For example, English is "super language", which has high value in the world. From the beginning of the 20th century, English has the added value of lingua franca, which can be used and communicated in most parts of the world. At the same time, English also has the added value of trade and knowledge exchange between different cultures. Therefore, English has emerged as a "super language" in the contemporary language. It can be said that when more and more resources are attached to a language, and the language will be more easily recognized and voluntarily learned by other countries or nationals. The successful transmission of a language to the outside world means that the country and nation have high values, and the country or nation has a high reputation. If a country's language is increasingly valued by the people of other countries, we can say that the country' $\mathrm{s}$ output of soft power has been successful. In today's fierce language competition environment, how Chinese has become a kind of ultra-super-language and becomes a more universal language. This is a question worthy of our consideration.

\section{ANALYSIS OF LANGUAGE COMMUNICATION}

From the perspective of human history, civilization is often divided into: "marine civilization" and "land civilization." Therefore, from the perspective of language communication and development history, language communication can also be divided into "land language transmission mode" and "marine language transmission mode". In the process of the propagation of language empire, the path, mode of dissemination, and effect of communication of "Land language" and "Marine language" are different

In the early history of mankind, due to the limitations of technology and geography, the history of the "land language" transmission mode was earlier than the "marine language" transmission mode. Due to the limitations of transportation 
technology, the early "land language" was based on geographical spread. The spread of "Land language" is often the spread of language between similar regions. The means of dissemination is spread across culturally similar and geographically adjacent regions. The people of the region consciously voluntarily learn the language of "prestige" people or nations. Therefore, in the "land language" mode of transmission, language communication can achieve good communication results. For example, the ancient Chinese nation has always been a model of culture, economy, and military in East and Southeast Asia. In East and Southeast Asia, the Chinese nation is a "prestige" nation. Regardless of military, economic, educational, cultural and scientific and technological aspects, the Chinese nation is at the heart of the region. As a result, ancient Chinese has become a highly valued language in a geographically similar area that has been voluntarily learned and accepted by other ethnic groups. At the same time, in the history of population migration in Asia, the Han nationality population has been at a high level. Due to various reasons, some Han people migrate to other regions of Asia, intermarry and reproduce populations. This kind of population integration has enhanced the willingness of people in the countries around East Asia and Southeast Asia to learn Chinese and Chinese culture. The same mode of transmission exists in Europe. For example, in Europe, the Germanic people defeated the Romans, but due to the high prestige and high value-added character of Roman culture and language, many European countries and nations inherited Roman culture and Roman language Latin. In the "Land language" transmission mode, due to the existence of long-term exchanges between ethnic groups and cultures, the gap between ethnic groups and cultures is small, and the language of a prestigious nation or country has high added value. The spread of language is good, but it is limited by geography, so the spread of "land language" is limited. For example, the spread of Chinese is limited to East Asia and Southeast Asia, and the spread of Latin is limited to Europe.

The "marine language" mode of transmission was later than the "land language" mode of transmission. The "marine language" mode of communication broke through geographical restrictions and spread through the ocean to larger and wider areas. The "Marine Language" mode of transmission originates mainly in Europe. Along with the advancement of European navigation technology, Europe has expanded its interests to other continents and opened up a mode of colonial communication. This language spread along with Europe' s overseas expansion in the colonies of other continents. The "marine language" mode of transmission was bloody from the very beginning, and the "marine language" mode of transmission was different from the "land language" mode of transmission. The "Marine Language" mode of communication is that different cultural exchanges did not communicate and communicate in depth before this time. Therefore, at the beginning of the mode of communication, there is a large gap between cultures, language differences, and forced audiences are not willing to accept language transmission. . However, in view of the current world language pattern, some languages that use the "marine language" transmission method have achieved great success. This is due to the formulation of language policy. In the "marine language" mode of transmission, Europe has formulated relevant language policies for the benefit, increased language added value, and the country's high prestige, etc., and has ensured a strong promotion of the implementation of language transmission. These language policies affect the language landscape of the world today. For example, the status of English and French in the language structure.

\section{ENLIGHTENMENT TO AMERICAN CHINESE COMMUNICATION}

\section{A. Integrate Soft and Hard Power for American-Chinese Communication}

From the perspective of the history of language communication, the country' $s$ hard power is a key factor in the dissemination. Now our country' $\mathrm{s}$ economic strength ranks second in the world. Chinese communication therefore follows the pace of the times and seizes the opportunity.

First of all, population is one of the important factors in the spread of language. Population reproduction is the most effective way to expand the population of language groups in language communication. We can see that there has been a dramatic change in the language landscape in Europe. The low reproduction rate of the original resident population of European countries is in sharp contrast with the high reproduction rate of the Arab population, which has caused the entire population of Europe to evolve in a way conducive to the spread of Arabic language. The same case also occurred in the United States. Samuel Huntington pointed out that under the theory of multiculturalism and diversity, there are more and more multinational mobile people who are conceptually indifferent to the United States. In areas where American immigrants live in concentrated areas, the immigration' $s$ language and culture have not changed, and the proliferation of population has caused many immigrants to influence the formulation of US policy. Language is the blood of culture and people. Does society need bilingual or multilingual issues? Samuel Huntington in his "Who Is an American? The Challenge of the National Character of the United States" is put forward: From the history of the United States, English plays an extremely important role in maintaining the integrity and unity of the United States. Therefore, in terms of the proportion of the population, for language transmission, our country' $\mathrm{s}$ language policy should ensure the use of Chinese, as well as guarantee the birth of the domestic population, as well as the introduction of policies encouraging Chinese in the United States to use Chinese and population reproduction. If China is to ensure the use of Chinese, it must ensure a certain amount of indigenous fertility, or encourage the birth of overseas Chinese in the United States, and use Chinese to train future generations.

Second, trade is an important factor in the spread of modern languages. The spread of English is positively related to its economic strength. Trade is the most natural and effective means of communication among different cultures and different language groups. Increase the exchange activities between China and the United States, promote the overseas trade of China's transnational corporations, and increase the added value of Chinese language. We look at English as an ultra-super language. The use of English outside the domain 
has enhanced the development of cultural industries in the United States and the United Kingdom, helping the United States to become a "world's cultural industry power." English has become the most frequently used language in world trade, which greatly increases the added value of English. At the same time, the successful overseas dissemination of English has also led to domestic employment and cultural international trade. The high value-added of English has made the nations of the world willing to learn English, and has paid time and money for it. This has provided the United States with its core values and its ability to disseminate "mountain civilization" and has achieved the goal of "victory without war". Therefore, in world trade, we should formulate appropriate language policies to help Chinese become a common language for different cultures and ethnic groups, that is, to realize the status of Chinese as an ultra-super language. We know that if a country or a nation has a strong influence in the trade in a large area, then the language of the country or nation is also relatively easy to achieve effective communication effects. The Chinese language becomes a super-super language in trade, which will also help China's national trade increase.

Furthermore, in the process of spreading Chinese, education and science and technology are effective means of language communication, low cost of use but highly profitable means. From the perspective of the history of language communication, we can conclude that if a language becomes a language of education and technology between language groups, then the language will largely be able to control or influence the behavior of the vast majority of communication audiences and thought. Take the overseas transmission of English and French as an example. The British and the French guided the colonial people through language policy education. The British are in India and the French are in North Africa. They have taken the initiative to lead the local elite in learning English or French, and have made English and French one of the hallmarks of the elite class and the ordinary class. Among the local ethnic groups, elites in order to maintain their class, they will voluntarily provide or create conditions for local acceptance and admiration of English or French in order to protect this intangible linguistic asset. As a result, English and French are more likely to become wealth for local elites who have the power to decide. Overseas Chinese language dissemination can refer to this language policy and formulate Chinese as one of the hallmarks of science and technology and culture. Forming a good Chinese language can bring some benefits to the elite. Let more elites like lawyers, doctors and teachers voluntarily learn Chinese for better and more job opportunities. Moreover, these elites accept Chinese culture more or less while accepting Chinese thoughts, and these groups of people can often restrict and guide the local policy.

The fourth point is that this is very important for the spread of Chinese, which is the increase in the military strength of the Chinese nation. Without escort of military strength, any language and cultural communication is prone to empty talk. From the perspective of the history of language communication and the current language pattern, language learners often fail to clearly identify other targeted language transmissions and use language transmission to achieve the idea of eradicating mistakes, which may jeopardize national security. Therefore, the country needs to ensure national security, build a stable language environment through the promotion of military strength, and spread the language overseas.

Finally, we will build and improve various cultural exchange models between China and the United States. Since the establishment of diplomatic ties between New China and the United States in 1979, the United States has set up a variety of foundation exchange models for the smooth dissemination of American language and culture in China. From the results, the U.S. foundation model has achieved very good results. Our country can learn and use this model to build and improve opportunities for students and teachers who are willing to learn Chinese and who come to study in China to use social groups and foundations as their communication subjects. This model will effectively provide an opportunity for the elites of the audience countries to feel the charm of the language and culture of the sponsoring countries, and thus influence the policy making of the dissemination of the audience.

\section{B. Chinese Teachers Trained for American K-12 Education System Should Be Localized}

With the development of China's economic strength, Chinese has officially entered the US K-12 education system, which is equivalent to our country's education time from kindergarten to high school, so the demand for Chinese teachers in the United States is increasing. At present, the biggest bottleneck for Chinese expatriate teachers in the United States is the problem of teacher, which is not for American equality of teacher of K-12. There is a big difference between the needs of Chinese international teachers trained in China and those of American teachers in primary and middle schools in the United States. Therefore, Chinese international teachers newly trained in China often do not have the qualification to enter the US K-12 public teaching system. In order to realize less costly and better teaching results, the development path of Chinese international education in the United States should train and support American teachers in the United States so that American teachers in the United States can meet American teacher laws and regulations.

First of all, since 1994, the U.S. government has formulated the National Security Language, the National Security Education Law, the Foreign Language Teacher Training Curriculum Standards, and the Foreign Language Teachers' Work Permit Standard. The United States has formulated laws and regulations to provide local people who are more proficient in Chinese for important areas of the United States. These areas include the military, trade, and diplomacy. Chinese has become one of the key languages for the United States. The cultivation of qualified primary and secondary school teachers for public elementary and secondary education in the United States has risen to the national security of the United States. Therefore, Chinese international education mentioned an unprecedented new height in the American K-12 education system.

Second, American primary and secondary schools need teachers who can communicate and teach in English and Chinese, who are well-acquainted with American culture, and who have American teacher qualifications and teaching experience in primary and secondary schools. At the same time, 
these teachers must also be people who can serve for a long time. Teachers in the US primary and secondary schools must participate in certification exams and long-term teaching practices after meeting the basic qualifications of the state' $\mathrm{s}$ teacher qualifications. After a series of assessments, they will be able to obtain teacher qualifications. Only Chinese who have a formal teacher qualification certificate in the state can become Chinese teachers.

Qualified Chinese teachers can help students use Chinese for discussion and research. The Chinese language teachers that we are cultivating in China are often subject to professional restrictions and cannot be well interdisciplinary. Finally, according to the laws of the United States, visas for teachers in the United States must be work visas, and visas for visits cannot be taught. In other words, visas issued by Confucius Institute teachers and volunteers make their status inaccessible to the K-12 public teaching system. If you can't enter the system and just pass the online school, then the expatriate teachers and volunteers can complete all the functions of the online school in China.

The Chinese international education students cultivated in China often do not have the conditions to engage in K-12 teaching. Therefore, the cultivation of American Chinese teachers should follow the principles of American localization. The localization of Chinese teachers also provides more jobs for native Americans while saving financial resources and providing teaching effects.

\section{CONCLUSION}

How to win Chinese in the fiercely competitive world language stage is an important research content for linguists. The author believes that the Chinese language will need to formulate relevant language policies. These language policies should take into consideration the following points: To ensure and increase the number of people who use Chinese. From the perspective of human history, population reproduction and outward migration are both important factors in the transmission of language; increase the added value of Chinese; attach importance to the use of the characteristics of the spread of the Internet + era, increase the use of Chinese and exposure in the Internet Increase the influence of Chinese language; attach importance to the overseas export of Chinese enterprises; and actively promote the active role of multinational corporations in the dissemination of Chinese; enhance the construction of the country while ensuring the growth of international trade, and increase the use of Chinese in international trade and science and technology Frequency, promote Chinese as a common language among international trade; promote the possibility of Chinese as a lingua franca of science and technology and culture; social groups and various funds subsidize the elite of the United States; attach importance to education and actively cultivate Chinese that meets the requirements of American laws and regulations. Teachers and the process of accelerating the localization of American Chinese teachers. While addressing employment, China has been guided to enter the U.S. formal education system.

\section{ACKNOWLEDGMENT}

The paper thanks the National Social Science Foundation of China (Grant NO. 15BYY054, the Project Leader: Zhu Lin), and the paper is one of the results of the phased research.

\section{REFERENCES}

[1] Zhu Lin, "Teaching Chinese as a Foreign Language based on Tone Labeling in the Corpus and Multi-Model Corpus" , Lecture Notes in Electrical Engineering, PP 51-59, 2013.

[2] Zhu Lin, Under the Chinese Language and Culture International Communication Strategy. July 2016.

[3] Samuel Huntington, The Conflict of Civilization and Reconstruction of the World Order, Beijing: Xinhua Publishing House, 1998.

[4] Samuel Huntington. Cheng Kexiong translates, Who is the American? The Challenge of American National Characteristics. Beijing: Xinhua Publishing House, the first edition in January 2010.

[5] Wang Jianqin, American "Critical Language" Strategy And China's National Security Language Strategy [J]. Journal of Yunnan Normal University (PHILOSOPHY AND SOCIAL SCIENCES EDITION), March 2010.

[6] Lu Jian Ming, Several Problems In The International Communication of Chinese. Chinese teaching and research in March.2013.

[7] Nicholas Ostre, Language Empire: World Language history, Shanghai: Shanghai people's publishing House, 2016. 